\title{
A utilização da tecnologia, oficinas e jornadas interdisciplinares para desenvolver a aprendizagem significativa da educação ambiental: um ato de cidadania
}

\author{
The use of technology, workshops and interdisciplinary journeys to develop \\ meaningful learning in environmental education: an act of citizenship
}

\author{
Tamiris Locatelli I
}

\section{RESUMO}

É necessário mais que apenas transferência de conteúdos, como defende Paulo Freire é preciso autonomia, nossos alunos necessitam estar frente ao seu processo de aprendizagem tendo um professor mediador. Possível solução a esse problema, os projetos, jornadas interdisciplinares auxiliam no desenvolvimento integral do conhecimento, por meio das resoluções de situações problemas reais, enriquecendo a aprendizagem, os recursos tecnológico aliado a estes, aproxima o aluno ao professor, levando a aprendizagem significativa. É função da escola, gerar aprendizagem, assim como, competências e habilidade necessárias para o convívio em sociedade. A Educação Ambiental é primordial nas escolas, é por meio dela que nossos alunos desenvolvem um engajamento social com ações e atitudes que visem garantia da qualidade de vida de nossas gerações futuras. Para tanto, o problema de pesquisa deste artigo tem como foco responder como as oficinas, jornadas interdisciplinares e a tecnologia contribuem para a formação da aprendizagem significativa da educação ambiental. Sendo objetivo geral realizar estudos acerca dos projetos interdisciplinares, oficinas, uso da tecnologia na educação e suas contribuições para a aprendizagem, desenvolvendo a consciência crítica nos alunos do ensino fundamental, adotando postura de respeito e valorização sobre as questões ambientais. A metodologia deste artigo foi desenvolvida através de pesquisas bibliográficas.

Palavras-chave: Ensino; Interdisciplinaridade; Jornadas; Ambiental; Aprendizagem.

\section{ABSTRACT}

More than just content transfer is needed, as Paulo Freire argues, autonomy is needed, our students need to face their learning process with a mediating teacher. Possible solution to this problem, the projects, interdisciplinary journeys help in the integral development of knowledge, through the resolution of real problem situations, enriching the learning, the technological resources combined with these, brings the student closer to the teacher, leading to meaningful learning. It is the function of the school, to generate learning, as well as the competences and skills necessary for living in society. Environmental Education is paramount in schools, it is through it that our students develop a social engagement with actions and attitudes that aim to guarantee the quality of life of our future generations. To this end, the research problem in this article focuses on answering how workshops, interdisciplinary days and technology contribute to the formation of meaningful learning in environmental

' Bacharel em Química. Servidora Pública, Governo do Estado de São Paulo. E-mail: tamirislocatelli@gmail.com. ORCID: https://orcid.org/0000-0002-7817-6917. 
education. The general objective being to carry out studies on interdisciplinary projects, workshops, the use of technology in education and their contributions to learning, developing critical awareness in elementary school students, adopting a respectful and appreciative attitude on environmental issues. The methodology of this article was developed through bibliographic research.

Keywords: Teaching; Interdisciplinarity; Journeys; Environmental; Learning.

\section{INTRODUÇÃO}

A hipótese deste artigo é a que as oficinas, projetos interdisciplinares e o uso da tecnologia promovem a aprendizagem significativa, uma vez que estes proporcionam a comunicação síncrona, assíncrona e a interação entre discentes e docentes, enriquecendo as aulas e tornando a aprendizagem mais dinâmica, interativa e motivam-te. Sendo, portanto, a forma ideal de se trabalhar conteúdo curriculares nos mais diferentes níveis de ensino. Segundo a teoria de Ausubel,

A aprendizagem significativa tem vantagens notáveis, tanto do ponto de vista do enriquecimento da estrutura cognitiva do aluno como do ponto de vista da lembrança posterior e da utilização para experimentar novas aprendizagens, fatores que a delimitam como sendo a aprendizagem mais adequada para ser promovida entre os alunos. (PELLIZZARI et al., 2002, p.39)

Falar sobre projetos, oficinais interdisciplinares e o uso da tecnologia, de modo a desenvolver a aprendizagem significativa é uma forma muito ampla para se desenvolver esse tema, portanto, visando facilitar o entendimento sobre as questões abordadas e o enriquecimento que o seu uso trás ao ensino, de modo que mais docentes busque implanta-los em suas aulas, torna-se necessário escolher uma área específica do conhecimento para o desenvolvimento desse trabalho, deforma a delimitar mais os conteúdos e levar ao entendimento maior do que está sendo colocado em xeque. Para tanto, abordaremos, o uso de projetos e oficinas interdisciplinares com o auxilio da tecnologia na Educação Ambiental visando à aprendizagem significativa que por sua vez refletirá na formação da cidadania da nossa sociedade.

A escolha da educação ambiental como área especifica desse trabalho, se justifica devido às questões ambientais estarem sendo consideradas cada vez mais urgentes e importantes na sociedade, pois o futuro da humanidade depende das relações 
estabelecidas entre a natureza e o uso pelo homem dos recursos naturais disponíveis. Portanto, a necessidade de conscientização e mudança de valores e atitudes para que os alunos vivenciem isso em seu cotidiano enfatiza a importância da Educação Ambiental, onde os conteúdos por esse tema abordado ultrapassam os muros escolares para além de nossos bairros, nossas cidades, nossos estados e países.

O conjunto de seres da natureza depende do meio ambiente para viver. Logo os bens da Terra são patrimônio de toda a humanidade, isso por si só justifica o trabalho da educação ambiental. Seu uso deve estar sujeito a regras de respeito às condições básicas da vida em sociedade e dentre elas a qualidade de vida dos que dependem desses bens.

Para desenvolver esse tema, tão importante e incrustado nos conteúdos curriculares que, no entanto, muitas vezes passam despercebidos,

É preciso fazer consideração sobre o lixo como um importante arsenal de matéria a ser aproveitada, como composto orgânico ou reciclado e o problema da produçãode materiais não degradáveis ( $P C N$ 's, 2001).

A melhor forma de se fazer essas ou inúmeras outras considerações é por meio de uma abordagem interdisciplinar, já que as situações problemas que encontramos e enfrentamos em nosso cotidiano, são todas de caráter interdisciplinar não havendo divisão entre os conhecimentos para sua resolução.

Dar a educação ambiental uma abordagem interdisciplinar é colocar em prática o diálogo comparativo entre áreas de saberes diferentes, levando a comunidade envolvida a refletir sobre os problemas ambientais de forma mais ampla. Na perspectiva social, as oficinas interdisciplinares proporcionam o exercício crítico e criativo de todos os envolvidos, promovendo oportunidades construtivistas de conhecimento e a democratização de saberes, resultados e soluções.

O convívio escolar é um fator determinante para a aprendizagem de valores e atitudes essenciais à Educação Ambiental. Considerando que a escola é um dos ambientes mais imediatos entre o aluno e conhecimentos com suas formas de serem colocados em práticas para transformar as relações do eu com a do cotidiano. 
Sensibilizar os alunos para serem cidadãos conscientes, aptos para decidirem e atuarem na realidade socioambiental de um modo comprometido com a vida, com o bem estar de cada um e da sociedade por meio de atitudes e cuidados com o meio ambiente através da reutilização, reciclagem e redução do lixo é um dever da escola e um dos objetivos dos docentes - formar para a cidadania.

Do ponto de vista acadêmico, ao abordar esse tema por meio dos projetos, oficinas interdisciplinares fazendo uso da tecnologia, se promove as competências e as habilidades necessárias para construção de saberes a cerca das questões ambientais, de modo que estes conhecimentos não se tornem esquecidos com o passar dos anos, e sim praticados em nosso dia-a-dia e passados para as gerações futuras.

O autor Paulo Freire (1996) no capítulo dois de seu livro, cita "ensinar exige a convicção de que mudar é possível": "Constatando, nos tornamos capazes de intervir na realidade, tarefa incomparavelmente mais complexa e geradora de novos saberes do que simplesmente a de nos adaptar a ela". (1996, p.30). Certamente Paulo Freire com essas palavras evidencia a importância que o professor exerce no meio em que vive e como é fundamental seus ensinamentos e engajamentos sociais para que comecemos a mudar o mundo primeiro acreditando no poder do conhecimento de depois, mudando "nosso quintal".

Ao refletir sobre as experiências exitosas, as oficinas e jornadas se impuseram como práticas relevantes na formação acadêmica, profissional e social de toda a comunidade. A partir dessa primeira impressão, foi necessário desenvolver ampla pesquisa teórica sobre a concepção de ensino e de aprendizagem significativa, a importância da interdisciplinaridade e da tecnologia para o desenvolvimento da aprendizagem significativa da educação ambiental.

Após, abordarmos como a interdisciplinaridade auxilia na educação ambiental torna-se necessário entender como a tecnologia pode ser utilizada como ferramenta educacional nessa área. 
Para Daniela Melaré, o grande avanço tecnológico possibilitou a compreensão da importância das tecnologias no processo de aprendizagem, pois essa prática passa a atender "a diversidade de aprendizagem e as necessidades que a sociedade atual exige" (2008, p.58)

A ideia de que tecnologias de informação e comunicação facilitam o processo de ensinoaprendizagem está ligada ao fato de que tecnologia entra na vida do homem para facilitar, desenvolvendo habilidades, tornando-os participantes da sociedade do conhecimento.

[...] tecnologias criam novas chances de reformular as relações entre alunos e professores e de rever a relação da escola com o meio social, ao diversificar os espaços de construção do conhecimento, ao revolucionar processos e metodologias de aprendizagem, permitindo à escola a um novo diálogo com os indivíduos e com o mundo.

Contar com o apoio das máquinas contribui imensamente para o desenvolvimento do conhecimento, pois, ela é uma ferramenta capaz de melhorar a prática pedagógica, por meio da estimulação, da participação e da intervenção dos processos de pensamento dos alunos. (LOCATELLI, 2018).

"[...] mais do que responder importa saber perguntar, levantar hipóteses, investigar e criar caminhos que possibilitem o exercício de estratégias de convívio no mundo virtual." (FRANCISCO; MEDEIROS; COLLA, 2003).

Ausubel defende que, para a aprendizagem significativa, é importante considerar, no processo de ensino e aprendizagem, todo conhecimento já construído pelo aluno, para que ele, de acordo com aquilo que já conhece, ou seja, por meio de seus conhecimentos, consiga assimilar o novo, transformando sua visão de mundo e promovendo transformações na visão de mundo compartilhada: "O processo ideal ocorre quando uma nova ideia se relaciona aos conhecimentos prévios do indivíduo." (Fernandes, 2011). As práticas promovidas pelas jornadas, oficinas e pelo uso da tecnologia requerem que os alunos mobilizem seus repertórios para que possa se relacionar com as propostas interdisciplinares, uma vez que elas apresentam situações de aprendizagem voltadas para a realidade da comunidade envolvida.

Paulo Freire (1996 e 2003) destaca a importância e a preocupação de compreendermos que a formação do conhecimento deve ocorrer de forma participativa, colaborativa, a qual torna o sujeito protagonista da construção do seu conhecimento. Os estudos realizados neste artigo evidenciam que é possível, como quer Freire, promover 
relações de ensino e de aprendizagem que coloquem o aluno como autor da sua própria trajetória de estudante, tornando-se o protagonista dos saberes construído. A autonomia é motivada nos projetos, oficinas e tecnologias porque as ferramentas utilizadas nelas permitem que problemas sejam formulados e que os alunos sejam o centro do processo (e não os conteúdos, como se dá no ensino tradicional). Nesse contexto, o professor se revela como mediador das relações de aprendizagem, democratizando a sua voz em um ambiente virtual em que todos se manifestam - ora de modo síncrono, ora de modo assíncrono -, fazendo a aprendizagem avançar.

Marco Silva (2010) entende que o papel do professor na sociedade digital é o de que se deve superar a visão de um mero transmissor de saberes para desenvolver a colaboração do aluno por meio da formulação de problemas e situações que possibilitam o diálogo e a interação de todos os envolvidos na aprendizagem, mais que formar bons profissionais, o professor deve auxiliar na formação social, formando alunos aptos a viverem em sociedade.

Assim, o problema de pesquisa deste artigo tem como foco responder à seguinte pergunta: como as oficinas, as jornadas interdisciplinares e a tecnologia contribuem para a formação da aprendizagem significativa? E como trabalhar com projetos interdisciplinares a educação ambiental, levando a prática da cidadania?

O objetivo geral é o de realizar um estudo bibliográfico acerca dos projetos interdisciplinares, oficinas, uso da tecnologia na educação e como as suas utilizações contribuem para a aprendizagem significativa, despertando e desenvolvendo a consciência crítica nos alunos do ensino fundamental, adotando postura de respeito e valorização sobre as questões ambientais, para garantir um meio ambiente saudável, trabalhando o ser humano e meio ambientes juntos.

Os objetivos específicos, portanto, visam a discutir a importância de práticas interdisciplinares e do uso de recursos tecnológicos para explorar e possibilitar a interação síncrona e assíncrona, garantindo excelentes relações de ensino e de aprendizagem. Conscientizando aos alunos, oportunizando reflexões sobre as questões ambientais e 
como nossas atitudes interferem no meio ambiente, transformando a realidade que vivemos. Mostrar como o ser humano participa da transformação do meio ambiente em que vive, e que suas interferências negativas têm causado danos catastróficos à natureza.

A metodologia deste artigo foi desenvolvida através de pesquisas bibliográficas realizadas em artigos científicos e livros, conforme a linha de pesquisa selecionada.

\section{APRENDIZAGEM SIGNIFICATIVA}

\subsection{Possibilidades para uma Educação de qualidade}

Os elevados níveis de insucesso nas disciplinas nos sistemas de ensino se tornaram um problema universal e alvo de inúmeras pesquisas. A busca de uma aprendizagem mais eficiente e eficaz está na associação entre conteúdos curriculares e estratégias pedagógicas ajustadas a necessidade de cada aluno. Para tanto, é um desafio para os professores tornar o ensino algo empolgante, motivador e atraente, para assim, diminuir o insucesso vivido pelos alunos. Diante disto à utilização de projetos, oficinas com o auxílio da tecnologia, possui potencial para revolucionar o sistema educacional, promovendo a cooperação entre alunos e uma aprendizagem mais ativa. (LOCATELLI, 2018).

Um dos desafios maiores é a formação de alunos que, como quer Paulo Freire, em Pedagogia da autonomia (1996), sejam protagonistas da construção de seus saberes. Segundo essa perspectiva, o professor deve criar condições para que os estudantes atuem de modo colaborativo, interagindo com seus pares e com o conhecimento construído pela comunidade aprendiz.

No entanto, isso se torna um grande desafio para nossas escolas, afinal, a escola do século XXI tem hoje como maior dilema conseguir desenvolver conhecimentos. A aprendizagem dos séculos anteriores não se encaixa mais em nossa realidade, a memorização e repetição, refletem hoje nos elevados números de evasão e "fracasso escolar". Para tanto cada vez mais novas estratégias, metodologias, e formas de desenvolver o conhecimento vem ganhando espaço e se instalando em nossas escolas. 
Sim, se tornou necessário fazer com que a aprendizagem fique mais contextualizada e conectada a realidade de nossos alunos. (LOCATELLI, 2018).

Diante desse dilema, evidencia-se a necessidade de buscar novas ferramentas e formas de ensinar e aprender, encontrando um novo caminho para melhorar o ensino que auxiliem e facilitem o ensino-aprendizagem, para que assim a escola consiga desenvolver uma aprendizagem significativa que gere em nossos alunos mais que apenas conhecimentos e sim um engajamento social, formando mais que bons profissionais, cidadãos capazes de transformar a realidade onde vivem e formar uma sociedade melhor para todos.

Visando a formação para a cidadania em nossas escolas, que, aliás, é uma das novas exigências da BNCC (Base Nacional Comum Curricular) que trás como objetivo a formação integral de nossos alunos por meio do aprimoramento e desenvolvimento de competências gerais que são necessárias não apenas em ambientes escolares, e sim para a vida em sociedade. Para tanto, desenvolver essas competências requer mais que o trabalho em disciplinas, é necessário, a união dos saberes por meio de uma linguagem interdisciplinar, afinal o que se busca é o desenvolvimento integral e isso só é alcançado quando o ensino até então trabalhado de modo fragmento, se junta formando um conhecimento aplicável em nosso dia-a-dia, é inadmissível que o conhecimento se detenha apenas as disciplinas.

Talvez, no momento em que o conhecimento, foi dividido em compartimentos - as chamadas disciplinas - até tenha sido uma boa ideia, já que facilita a absorção e o trabalho dos saberes, no entanto, hoje esta forma de classificar o conhecimento tornou-se muito artificial, pois, os problemas ou situações-problemas como chamamos, que encontramos em nosso cotidiano, dificilmente se encaixa em uma disciplina apenas, já que problemas reais adotam uma abordagem interdisciplinar, esse exemplo se encaixa perfeitamente sobre as questões ambientais, onde dentro deste mesmo tema há estudos que abordam física, química, biologia, psicologia, sociologia, história geopolítica, geografia, etc., portanto, para abordar o tema meio ambiente é necessário enfocar as questões como um 
todo não apenas em compartimentos. Para que isso seja feito, a forma de trabalho mais adequada é por meio do uso de projetos, jornadas ou oficinas interdisciplinares. (CHAVES).

No Brasil, nos anos 1960, Paulo Freire é destaque na educação brasileira com a introdução de problemas políticos e socioculturais no processo escolar, através da educação libertadora e os chamados temas geradores. Suas ideias são conhecidas mundialmente e divulgadas através de seus livros, dentre eles "Pedagogia do Oprimido" e "Pedagogia da Autonomia". Jurjo Santomé e Fernando Hernandez, a partir da década de 1990 (Espanha), propõem o currículo integrado e os projetos de trabalho, que vão influenciar propostas pedagógicas e documentos oficiais brasileiros. Temos também a contribuição de Antoni Zabala, no início deste século, que propõe o projeto educativo abordado por um enfoque globalizador fundado na interdisciplinaridade. (SOARES, 2012, p.4). Isso nos leva a concluir que o trabalho interdisciplinar não é uma proposta nova em nossas escolas, e sim, que já se encontra nelas (em algumas mais que em outras) há certo tempo.

Segundo Moura e Barbosa, (2017) a utilização de projetos na área educacional apareceu devido aos obstáculos encontrados em nosso sistema de ensino atual, onde a escola passa a conviver com os elevados números de alunos que não aprendem o que proporciona elevados números de evasão escolar, em contra partida a essa realidade escolar, os projetos vieram com a finalidade de reformar o sistema educacional, auxiliar a inclusão de tecnologia, integrar escola e comunidade, etc. De fato são inúmeros os benefícios trazidos por sua utilização, dessa forma, portanto, o resultado de seu uso vem se consolidando cada vez mais.

Como definido por Moço (2011) os projetos estão mais populares que nunca, pois, trazem a vida real para sala de aula, tornando a aprendizagem contextualizada e com significado, deixando os conteúdos a serem trabalhados mais fáceis e empolgantes. Um projeto envolve sempre uma situação-problema, abordando o conhecimento em um todo. Assim podemos concluir que o uso de um projeto será a forma ideal de se trabalhar a Educação Ambiental em sala de aula. Moço, 2011, ainda cita que o uso de projetos para 
trabalhar a natureza e a sociedade é totalmente adequado, pois, aproxima as crianças a práticas sociais pela busca e apresentação de informações.

Tanto as oficinas, jornadas quanto à tecnologia quando pensadas do ponto de vista interdisciplinar e quando utilizam ferramentas de interação síncrona e assíncrona, permitem a criação de um esteio para que todos os envolvidos encontrem modos de participação na construção das relações de ensino e de aprendizagem. Assim como defende Paulo Freire, o aluno deixa de ser um mero ouvinte de saberes tendo o professor como detentor do conhecimento, e se transforma no autor principal da aprendizagem, tendo na figura do professor um mediador, por fim, nosso aluno está apto a ser inserido em toda uma vida de saberes e conhecimentos, pois, aprendeu na escola a autonomia para aprender.

A metodologia de Projetos Interdisciplinares possibilita relações e conexões entre as diferentes áreas do conhecimento. A criança é desafiada a estabelecer articulações entre as informações com as quais entra em contato e a diversidade de pontos de vista dos colegas compartilhados no grupo, construindo sua visão pessoal sobre os temas propostos. É mais que conhecer algo é refletir, questionar, propor soluções sobre o que se conheceu, a fim de formar suas próprias conclusões que estarão fundadas em suas experiências de vida, sua realidade e suas expectativas futuras.

Os projetos pedagógicos interdisciplinares são modos de organizar o ato educativo que indicam uma ação concreta, voluntária e consciente que é decidida tendo-se em vista a obtenção de algo formativo, determinado e preciso. É saber ultrapassar, na prática escolar, de uma situação-problema global dos fenômenos, da realidade fatual e não da interpretação técnica já sistematizada nas disciplinas. (SOARES, 2012, p.3).

A proposta de projetos pedagógicos interdisciplinares rompe com os paradigmas da pedagogia tradicional centrada na exposição de conteúdos pelos professores. Esse novo modelo propõe que o docente abandone o papel de "transmissor de conteúdos" e adote uma postura de pesquisador, de organizador do processo de ensino aprendizagem. E o aluno, por sua vez, passe de receptor passivo a ator do processo. (SOARES, 2012, p.4). 
Porém, o simples uso de um projeto não garante a aprendizagem, para que um projeto alcance seus objetivos é muito importante à escolha do tema. Este deve fazer sentido para a criança e deve ser de fácil assimilação e aplicação no cotidiano de nossos alunos. Há vários estudos já publicados a cerca de como trabalhar com projetos e oficinas com o objetivo de dar respaldo a professores que ainda não entraram em conta to com esse tema.

Com o uso das tecnologias nos projetos interdisciplinares, o professor se torna mais próximo do aluno, sendo capaz de adaptar suas aulas, fazendo com que o aprender ocorra por meio de descobertas, desenvolvendo o conhecimento de forma integrada. $O$ computador, uma das grandes ferramentas da era tecnológica, assim como o uso de projetos e oficinas, coloca os alunos diante de situações problema tendo que utilizar toda sua estrutura cognitiva para buscar a solução. Dessa forma, a tecnologia aliada a projetos e oficinas, se torna um poderoso instrumento no sistema de ensino, renovando os métodos tradicionais, motivando os estudantes, permitindo melhores ângulos de análise, auxiliando na inclusão, proporcionando maiores experiências e estimulando uma participação mais ativa do aluno. (BRAGA, 2001).

Nesse contexto, os professores assumem, plenamente, um papel mediador, dividindo suas vozes entre si e com todos os alunos, os quais determinam, segundo decisões próprias, suas trilhas, seus processos, sua trajetória da aprendizagem. Autônoma (Freire, 1996), toda a comunidade formula problemas e busca, a partir dos conflitos cognitivos gerados, saltos para novas aprendizagens.

Sem dúvida, há uma clara diferença entre o que se privilegia nessa metodologia progressista, se comparada às tradicionais, cujo foco permanece sempre sendo o conteúdo. Tais práticas evidenciam o que o professor Freire defendeu ao longo de toda a sua obra (1996 e 2003), ao afirmar que as mudanças em educação são necessárias e possíveis, para que seja preservado o caráter complexo da vida.

Para fugir à superficialidade que as sociedades tecnicistas buscam impor e para preservar a complexidade da tessitura dos seres e dos contextos, é necessário reanimar a 
sala de aula, garantindo, a um só tempo, a sua unidade e diversidade. Tendo o ensino, tradicionalmente, separado as disciplinas de modo a impor limites artificiais entre os saberes, é preciso fazer um esforço a fim de colocá-los em diálogo, refletindo, na aula, a complexidade da vida:

Difunde-se um conhecimento fragmentado e exige-se um indivíduo por inteiro. Procurase fazer com que o aluno memorize o máximo de teoria possível, e cobra-se dele, no mercado de trabalho, a formação prática necessária a uma boa atuação na empresa. Deixa-se o aluno fora do processo, alienado, e exige-se um cidadão crítico, participativo, inserido no contexto (KLEIMAN, 1999, p.14).

A superação da fragmentação do ensino só pode se dar, segundo Ângela Kleiman, quando os saberes escolares são pensados de modo mais abrangente e segundo a lógica da interdisciplinaridade, que prevê a interferência de uma disciplina na outra, transformando-a e sendo transformada por ela.

Com isso, os alunos, protagonistas, vivem a realidade na escola e a escola, por sua vez, chega à realidade deles, o que cria condições para o desenvolvimento das suas capacidades críticas e criativas, as quais contribuem decisivamente para o progresso ético dos indivíduos e da coletividade.

Quando nos referimos ao uso da tecnologia em oficinas e jornadas, independentemente do nível de ensino, há a necessidade permanente de promover a integração dos saberes. Elas evidenciam a possibilidade de se construir um uso da tecnologia de qualidade e que contribua para a real democratização do ensino e da sociedade e para uma aprendizagem mais significativa. Quando um aluno, experiência tempos significativos por meio dos quais ele se reconhece como partícipe da construção dos saberes, sente-se mais motivado para projetar essa vivência escolar na sua realidade, recuperando a capacidade de suportar seus conflitos, atritos, e lidar com eles. Nesse movimento dialético, realizado pelo diálogo síncrono e assíncrono, os sujeitos compartilham aprendizagens autonomamente, assumindo a responsabilidade plena por suas ações, escolhas e decisões, tornando-se "radicalmente éticos": 
"...a dialogicidade verdadeira, em que os sujeitos dialógicos aprendem e crescem na diferença, sobretudo no respeito a ela, é a forma de estar sendo coerentemente exigida por seres que, inacabados, assumindo-se como tais, se tornam radicalmente éticos." (FREIRE, 1996, p. 59)

Um modelo como o das oficinas e das jornadas interdisciplinares convida o aluno a mobilizar o que sabe a sua visão de mundo, o seu repertório, e a avançar em direção ao que lhe é proposto. Nesse movimento, o estudante assimila o novo e transforma o seu olhar. Segundo Ausubel, a aprendizagem só é significativa se ela se concretiza essa relação entre os conhecimentos prévios e as situações de aprendizagem:

A aprendizagem significativa não é sinônimo de aprendizagem de material significativo. Em primeiro lugar, o material de aprendizagem apenas é potencialmente significativo. Em segundo, deve existir um mecanismo de aprendizagem significativa. O material de aprendizagem pode consistir em componentes já significativas (tais como pares de adjetivos), mas cada uma das componentes da tarefa da aprendizagem, bem como esta como um todo (aprender uma lista de palavras ligadas arbitrariamente), não são 'logicamente' significativas. Além disso, até mesmo o material logicamente significativo pode ser aprendido por memorização, caso o mecanismo de aprendizagem do aprendiz não seja significativo." (AUSUBEL, 2000, p.1, itálico do autor).

A aprendizagem é significativa nas oficinas e jornadas interdisciplinares com o uso da tecnologia, porque o material disponibilizado e os mecanismos de aprendizagem são significativos, na medida em que provoca a comunidade a colocar seu repertório em função das novas perspectivas apresentadas por toda a comunidade.

Os professores dividem suas vozes com os alunos e proporcionam a formação de um concerto de saberes que vai sendo tecido por cada sujeito e, também, pela coletividade.

Posteriormente, os alunos continuam a construir coletiva e individualmente os conhecimentos expressos pela linguagem escrita. Mediada por todos os professores e alunos a tarefa de organizar os sentidos sugeridos é dos leitores (professores e alunos), que, com autonomia, organizam aprendizagens significativas.

\subsection{Tecnologias a ferramenta para as oficinas e jornadas interdisciplinares}


Iniciaremos esse subcapítulo já abordando as principais vantagens que o uso da tecnologia trás para a educação. Destacamos, estão que além da comodidade ao acesso, uma vez que o aluno poderá acessar seus conteúdos de estudo, independente de onde estiver, o aluno também, torna-se capaz de acessar e se organizar com horários para estudo de acordo com suas disponibilidades. Outra vantagem que a tecnologia trás é levar o conhecimento para além dos muros da escola, dessa forma o aluno tem todo material disponível sobre o tema que quiser na palma de sua mão, podendo acessá-lo com facilidade sempre que for necessário levando o conhecimento a todas as regiões do país.

A tecnologia certamente é um excelente mediador de conteúdos, melhorando sua forma de apresentação e exploração, saindo do tradicionalismo, por meio da utilização de softwares, fóruns, blogs e chats, jogos educativos, recursos interativos, etc. A utilização de tecnologia possibilita para a educação um novo desenvolvimento de trabalhos pedagógicos, enriquecendo as aulas e tornando-as mais interessantes. Em prol de uma aprendizagem mais rica, mais inovadora e atraente não se pode mais fugir da tecnologia nas escolas, o futuro do sistema educacional inquestionavelmente está entrelaçado à tecnologia. (LOCATELLI, 2018).

Diante desse avanço tecnológico no ensino, é fundamental que exista uma organização centrada na qualidade da educação que será oferecida e na forma como será disponibilizado todo o conteúdo para estudo. Sendo assim, surge a necessidade de inovar e se adaptar às novas tecnologias voltadas para essa finalidade.

\footnotetext{
A tecnologia simplesmente possibilitou uma grande fonte geradora do pensamento. $\mathrm{O}$ pensamento recebe uma série de elementos que passaram por todos os eixos de percepção, memória e atenção. Esses elementos são previamente modificados pelo espaço virtual, relacionando-se e interagindo, portanto, com uma informação diferenciada e que exige outras formas de conexões e relações, muito mais em rede, interconectadas e carregadas de uma diversidade de opiniões e formatos intelectuais distintos (MELARÉ, 2009, p.60).
}

Como já mencionado, as novas tecnologias além de permitir acesso interativo ao conhecimento também auxiliam na comunicação entre professores e alunos auxiliando para uma aprendizagem colaborativa, assim, em conjunto com as oficinas e jornadas 
interdisciplinares, ambos promovem maior volume de informações e disseminação dos mesmos de forma síncrona e assíncrona, tornando os envolvidos interligados, além de eliminar a sensação de isolamento, fomentando a curiosidade e a busca pela aprendizagem.

E o professor nesse processo? Será que a tecnologia substituirá o professor em sala de aula? Certamente o maior medo dos professore a cerca da tecnologia é exatamente isso, que esta acabe por substituí-lo em sala de aula, talvez, seja este o maior degrau que encontramos para a implantação da tecnologia nas escolas, o medo e o receio dos docentes trazidos pela falta de informação ou ainda por informações erradas a cerca deste assunto, que acabam tornando a tecnologia uma concorrente ao professor e não uma aliada.

No entanto, ao usar a tecnologia o professor é fundamenta, pois, nele é que estará centrado o papel de mediador, é o professor que deve procurar desenvolver a aprendizagem significativa por meio do processo dialógico, visando o conhecimento prévio do aluno para que faça sentido o conteúdo que ele está aprendendo e, ao mesmo tempo, assimile toda a nova informação adquirida durante essa interação. Para Masetto (2013), o processo de aprendizagem é um processo de mudança construído pela participação dos alunos por meio de pesquisas e troca de experiências, bem como diversas situações que ocorrem durante o processo pedagógico, mediado pelo professor.

A tecnologia por si só não gera o aprendizado dispensando o papel do professor, é apenas uma ferramenta disponível para melhorar o ensino-aprendizagem. Tecnologias não dispensam o professor de química, e sim auxiliam e aprimoram técnicas fazendo com que trabalhem de maneira diferente em sala de aula, deixando para traz o modelo de ensino tradicional. O professor deve possuir muita responsabilidade, coerência e bom senso para assim atingir as finalidades pedagógicos, tornando os alunos indivíduos ativos no processo de construção do conhecimento. (LOCATELLI, 2018)

Da mesma forma ocorre quanto às jornadas e oficinas interdisciplinares, tal ferramenta garante a participação de todos, onde discentes elaboram perguntas aos docentes, contextualizam o aprendizado de forma mais aprofundada, conversam com colegas de turma sobre o novo conteúdo e construir novos saberes e levam os 
questionamentos e aprendizagens para suas comunidades. Portanto, garante a não exclusão de discentes, proporcionando o pensamento crítico, o aprendizado integrado por diversas disciplinas e a aplicabilidade de todo o aprendizado no contexto profissional e atual, deixando de atuar apenas como um espaço de transmissão do conhecimento.

Por fim, além dessas ferramentas e recursos se apresentarem como instrumento de aprendizagem, pode ser utilizado como instrumento de avaliação dependendo da proposta, destacando-se como um espaço completo para as práticas que envolvam interação, reflexão, ação, transformação, construção e avaliação. Vale destacar que a avaliação a cerca de uma proposta interdisciplinar vai muito além de classificar alunos por meio de notas, estamos trabalhando o desenvolvimento integral do aluno e é isso que devemos avaliar, levando em consideração suas participações, evoluções os objetivos alcançados, etc. dessa forma a avaliação deve se dar em processo sendo contínua durante todo o desenvolvimento do projeto.

\subsection{Importância de uma aprendizagem significativa na educação ambiental}

Muitas vezes não nos damos conta que, aprender é um processo muito complexo, isso se justifica quando pesquisamos os resultados dos sistemas educacionais, é crescente o "fracasso escolar" entre nossos jovens. Na busca da melhora da aprendizagem de nossos alunos, cada vez mais, procuramos recursos que possam facilitar a aprendizagem. Dentre esses recursos, os projetos vêm ganhando muito espaço em nossas escolas e estão proporcionando resultados significativos na melhora da aprendizagem. (MOURA; BARBOSA, 2017).

A aprendizagem significativa é importante em qualquer área ou disciplina em todos os setores da vida, já que é por meio dela que sabemos que os conteúdos aprendidos não serão esquecidos em uma semana e sim que nossos alunos irão leva-los para a vida toda.

À medida que percorremos as séries iniciais do Ensino Fundamental, é de grande importância que levemos a eles problemas da atualidade para que possam construir instrumentos de atuação e se posicionem diante desses temas - como as questões 
ambientais. No entanto, isso deve ser feito do modo muito sutil afinal não devemos esquecer que ainda são crianças. Portanto, para trabalhar problemas ambientais devemos sempre entrar em contato com conhecimentos prévios construídos e trazidos por eles e assim como ao subir de uma escada "um passo de cada vez" introduzirmos novos questionamentos sobre a Educação Ambiental. O uso do projeto a cerca da educação ambiental, trás essa enorme vantagem, a de possibilitarem habilidades e competências de observação, registro, comparação, escuta, expressão oral e argumentação.

O meio ambiente é um assunto que deve ser trabalhado, dentro e fora dos espaços escolares por meio de ações, projetos e debates que envolvam o aluno e o leve a refletir sobre sua relação com o meio onde vive. Nesse sentido o trabalho com educação ambiental, insere o aluno as questões de sustentabilidade, levando a ações humanas com a finalidade de suprir as necessidades do ser humano sem intervir nas gerações futuras, usando com consciência os recursos naturais sem agredir o meio ambiente, por meio do uso e desenvolvimento energia renováveis, reciclar os resíduos sólidos, gerando renda e diminuindo o lixo no solo e na água. Assim reduzir, reutilizar e reciclar (política dos 3Rs) passa a ser ações necessárias para que a natureza possa ser preservada e continuar garantindo o sustento à vida humana.

O Ministério do Meio Ambiente por meio da Política Nacional de Educação Ambiental define educação ambiental como sendo um processo no qual, os indivíduos e a sociedade constroem valores sociais, conhecimento, atitudes, habilidades e competências que visem á conservação do meio ambiente, buscando qualidade de vida e sustentabilidade. Á inúmeras outras definições sobre a educação ambiental, como a das Diretrizes Curriculares Nacionais para a Educação Ambiental, a da Conferência Subregional de Educação Ambiental para a Educação Secundária - Chosica/Peru (1976) e a da Conferência Intergovernamental de Tbilisi (1977), no entanto todas se fundem nessa mesma reflexão. (MINISTÉRIO DO MEIO AMBIENTE).

Partindo dessa definição de educação ambiental, chegamos à educação do nosso sistema de ensino, onde educação e educação ambiental caminham lado a lado na busca 
de formação da cidadania, logo, não á como deixar a escola de fora da educação ambiental, uma vez que ambas tem o papel fundamental na formação de cidadãos. Conclui-se assim, que é dever da escola engajar seus alunos nas causas ambientais, assim como desenvolver trabalhos sobre estas questões de forma a desenvolver uma consciência responsável e sustentável em seus discentes. Desenvolver ações educativas junto aos alunos sobre questões e problemas ambientais, especialmente na preservação e a reciclagem, através de métodos ativos, conscientizando os alunos da necessidade de proteção ao meio ambiente, comprometendo-se com a preservação e a defesa como cidadãos responsáveis.

A Escola por sua vez também é responsável pela sociedade. A Educação Ambiental é uma forma abarcante de educação, através de um processo pedagógico participativo que procura infiltrar no aluno uma consciência crítica sobre os problemas do meio ambiente.

A Educação Ambiental é de extremamente importante para a formação de cidadãos, podendo ser abordado de diferentes formas e maneira contribuindo para a aquisição de seus conhecimentos, isso porque, nossos alunos mesmo que ainda crianças, trazem consigo uma enorme bagagem sobre esse tema, seja por meio de conhecimentos adquiridos em jornais, reportagens, ou até mesmo ensinados pelos pais, o que torna o tema atraente e motivador.

"A Educação Ambiental é uma vertente da educação direcionada aos assuntos relacionados à interação homem-ambiente, despertando uma consciência crítica sobre os problemas ambientais". (DIAS, 2000.).

A relação do homem com o ambiente na pré-história ocorria de uma maneira natural onde ele não transformava e nem modificava a natureza. Mas com o passar dos tempos isso foi mudando, o homem começou a ter o controle sobre a natureza fazendo as transformações para as suas satisfações, com essas modificações cada vez mais foi ficando descontrolado o equilíbrio que sempre existiu em nosso planeta, hoje, o meio ambiente está totalmente modificado, e com isso vem às consequências. 
É de grande importância se desenvolver a educação ambiental em nossas escolas, para nossos alunos entenderem as interações homem natureza como algo natural existente desde a pré-história, porém, com interações completamente diferentes das atuais. O homem pré-histórico não transformava nem controlava o meio onde vivia, pois, não possui o conhecimento necessário para tanto. Com sua evolução, o homem começou a adaptar o meio ambiente às suas necessidades em busca de sua sobrevivência. No caminho da evolução, o homem acabou perdendo a sua ligação com o meio ambiente, o homem deixou de ser parte integrante da natureza, tornando-se predador do seu próprio meio. (ALBANUS; ZOUVI, 2012).

Os alunos atuais, já se encontram inseridos no modelo capitalista, esse mesmo modelo responsável pela degradação ambiental em razão da intensa exploração dos recursos naturais, de um consumo não consciente, além das mais diversas formas de poluição. (DIAS, 2000).

Entre as décadas de 70 e 80 começou-se a disseminar a consciência ambiental entre vários grupos da sociedade e cada década essa consciência encontra-se mais consistente tomando cada vez mais espaço e força. Nesse contexto, emerge a educação ambiental responsável por essa expansão de opiniões, formando o povo e líderes para a mudança de atitude em relação ao nosso planeta.

A educação ambiental forma cidadão mais conscientes, inspirando o sentido de responsabilidade, aprimorando o sistema de produção, para que o capitalismo não cobre um preço tão alto como a destruição de nosso planeta. (ALBANUS; ZOUVI, 2012).

A Educação Ambiental busca despertar a consciência da população quanto aos problemas ambientais gerados pelas atividades humanas. Portanto, é uma ferramenta de importância fundamental para o desenvolvimento responsável da humanidade gerando uma conscientização ecológica e mudanças de atitudes contribuindo para a formação humana. (DIAS, 2000.)

É chegada a hora da mudança de atitude, antes que seja tarde demais! As mudanças climáticas batem a nossa porta, cada vez com mais intensidade, não podemos mais fechar 
nossos olhos para os efeitos que o homem causou na natureza, citamos como exemplos, vários acontecimentos catastróficos que vivemos nas ultimas décadas, como: inúmeros furações, terremotos, aquecimento global, buraco na camada de ozônio, tanto quanto inúmeros outros fatos e fenômenos que vem colocando a existência humana em xeque, se quisermos garantir a nossa subsistência devemos garantir primeiro o futuro de nosso planeta.

Antigamente o homem convivia com a natureza em perfeita harmonia e respeito, mas ao deixar de ser parte integrante dela, começou a dominá-la, pensando somente nos lucros e progressos pra si mesmo. Nas últimas décadas, a discussão a respeito da questão ambiental ganha uma maior dimensão, uma vez que, a sociedade cada vez mais é afetada diretamente por riscos e agravos socioambientais.

Partindo do que foi estudado no livro Eco pedagogia de Albanus, e em reportagens dos principais desastres ambientais, levando em conta as relações que o homem vem mantendo com o meio ambiente, de que formas ele tem aproveitado dos recursos que ela oferece ao longo dos anos, e como a natureza vem mostrando seus sinais a esse tipo de comportamento humano, um projeto interdisciplinar seria perfeito para trabalhar esse assunto, visando à conscientização dos alunos do ensino fundamental, a fim de discutir e responder as questões centrais quanto ao meio ambiente, levando a reflexão de como o homem tem se relacionado e usufruído dos recursos que a natureza oferece? Como a natureza vem reagindo? De que maneiras podem modificar esse quadro de destruição e ameaça que ronda sobre todos nós? E por meio desses questionamentos levarem os alunos a mudanças de atitudes efetivas nas comunidades a que estão inseridos, levando informações a seus vizinhos, familiares, amigos, etc.

Abaixo, são citamos as definições de Educação Ambiental, que em suas palavras já enfatizam sua importância, segundo a Lei n 9795/1999, a Diretrizes Curriculares Nacionais para a Educação Ambiental e Conferências "A educação ambiental é um processo de reconhecimento de valores e clarificações de conceitos, objetivando o desenvolvimento das habilidades e modificando as atitudes em relação ao meio, para entender e apreciar 
as inter-relações entre os seres humanos, suas culturas e seus meios biofísicos. A educação ambiental também está relacionada com a prática das tomadas de decisões e a ética que conduzem para a melhora da qualidade de vida" (CONFERÊNCIA INTERGOVERNAMENTAL DE TBILISI, 1977).

A educação ambiental é responsável por expandir opiniões, formando o povo e líderes para a mudança de atitude em relação ao nosso planeta, obtendo cidadãos mais conscientes e responsáveis, aprimorando o sistema de produção, para que o capitalismo não cobre um preço tão alto como a destruição de nosso planeta. A degradação ambiental evolui a passos rápidos, em nome do crescimento produtivo e econômico gerando o desenvolvimento, o homem tornou-se um ser que destrói culturas para estabelecer economias. A humanidade evolui para o caos, e a natureza já demonstra os sinais disso, por meio das catástrofes ambientais, a natureza modificada pela história, atinge a sobrevivência humana colocando-nos contra a parede. O homem que tudo domina luta contra a natureza sem se preocupar com seus impactos. Não podemos nos esquivar de nossas culpas, a natureza é o resultado da ação coletiva, de nossas projeções, desejos e angústias. (ALBANUS; ZOUVI, 2012).

De acordo com o trecho da A Carta da Terra, "estamos diante de um momento crítico na história da terra", o mundo passa por uma sombra de medo, medo de deitar para dormir e acordar soterrados, com sua família e a natureza enterrados vivos.

A educação ambiental faz parte do cotidiano escolar. Em termos de educação essa perspectiva contribui para evidenciar a necessidade de um trabalho vinculado aos princípios da dignidade do ser humano, da participação, da responsabilidade, da solidariedade da equipe.

É importante desenvolver a conscientização dos alunos acerca da preservação do meio ambiente, valorizando e ampliando pequenas atitudes futuras tornando cidadãos cientes da responsabilidade de cada um. É preocupante, a forma como os recursos naturais e culturais brasileiros vêm sendo tratados. Poucos produtores conhecem ou dão valor ao 
conhecimento do ambiente especifico em que atuam. Muitas vezes pensando só no lucro esquecem-se das consequências como foi o caso da tragédia em Mariana.

É imprescindível a abordagem e o trabalho da consciência e a responsabilidade das crianças, desenvolvendo o espirito humano, para que, eles posam olhar para natureza com gratidão e humildade.

Portanto, os educadores têm o dever de trabalhar a educação ambiental nas escolas, para que assim garantam a formação de cidadãos conscientes que se preocupem com o futuro do nosso planeta assim como com nossa subsistência. Logo o projeto, é importante não apenas para os alunos onde é desenvolvido, mais para toda a sociedade, é uma semente sendo plantada para germinar, crescer, florescer e gerar mais frutos!

\section{PROJETO INTERDISCIPLINAR}

\subsection{Um projeto/ oficina interdisciplinar em educação ambiental}

Os projetos e oficinas interdisciplinares mais especificamente, são trabalhos que não se encaixam unicamente dentro de só uma disciplina, isso geralmente acontece quando trabalhamos propondo problemas reais. Dentro da Educação Ambiental, possuímos inúmeros elementos que se enquadram em disciplinas diferentes como: Português, Ciências, Artes História, Matemática, Geografia, Inglês, entre tantos outros componentes curriculares que podem abordar esse tema.

Assim concluímos que é impossível abordar o meio ambiente dentro de uma abordagem disciplinar, tornando-se interdisciplinar, por meio do trabalho conjunto dos docentes da escola. (CHAVES).

Quando abordamos projetos interdisciplinares nas escolas sobre meio ambiente, acabamos por desenvolver essa nova disciplina (educação ambiental), a qual é responsável pela formação humana e para a cidadania.

É fundamental para tanto o trabalho com atividades que venham possibilitar o desenvolvimento de sensibilidade e do senso crítico dos alunos e o engajamento desses 
nas questões ambientais por meio de mudanças de atitudes que levará a concretização do aprendizado.

A sensibilização do educador deverá ser conseguida por uma relação prazerosa dele com o processo. Assim sendo, destaca-se na educação ambiental a importância do aspecto lúdico e criativo das atividades e procedimentos utilizados para envolver completamente o aluno, ou seja, abarcar tanto o seu lado racional como o emocional - o que deve ser considerado em plano de ação.

Sempre ao iniciar um projeto, torna-se necessário uma conversa informal sobre o meio ambiente de modo a que sejam levantadas as opiniões dos alunos acerca do ambiente, suas observações do meio social de pertencimento, buscando enfocar nos conhecimentos prévios dos alunos sobre o meio, suas intervenções e inter-relações com ele. Também é extremamente necessário que o professor fale e desenvolva o tema abordando assuntos relevantes para a compressão das questões ambientais: Conceito de meio ambiente, relação homem natureza, degradação ambiental, desastres no mundo, que levam a curiosidade do aluno a cerca do que será trabalhado. Para isso pode ser realizadas leitura de textos e notícias dos desastres ambientais, palestras com especialistas em questões ambientais, quais transtornos tem trazido as famílias e ao planeta, através de produções de textos e desenhos com história em quadrinhos demonstrando seu entendimento. Realizar observações e registros no entorno da escola, como as pessoas utiliza os recursos da natureza, e sua família o que faz com o lixo, como usa a água, como trata a natureza? É fundamental esse trabalho com essas informações que servirão de embasamento teórico para os alunos, afinal a finalidade do projeto é que eles reflitam sobre as questões ambientais e tirem suas próprias conclusões e não que o professor traga tudo pronto e apenas "despeje" conteúdos e saberes sobre seus alunos.

Também é fundamental colocar em prática os conhecimentos adquiridos - é por meio de atitudes que alcançamos a mudança - entrando nessa fase, a confecções de matérias recicláveis, como garrafas pet para confecção de brinquedos, palitos de picolés 
para fazer portas retratos e ensaio da música, formulação de teatro trazendo o mundo que quero para o amanhã, etc.

É essencial em um projeto a socialização, para que o trabalho desenvolvido faça sentido e não fique preso entre quatro paredes de uma sala, podendo ser feito um mural no pátio escolar com a exposição de todo material feito no decorar do ano, desde os textos e desenhos produzidos, assim como os materiais confeccionados de produtos recicláveis, e apresentação visual da música e "hora de preservar de Marcelo Santa Cruz", etc. Assim os resultados obtidos são expostos para toda a escola, pais e comunidade.

\subsection{Educação Ambiental: sua abordagem interdisciplinar com as disciplinas do currículo}

\subsubsection{Português}

Leituras diferenciadas: textos, notícias poemas, letras de música como: "chovendo na roseira (tom Jobim) e "planeta água" (Guilherme Arantes);

Leitura coletiva do livro paradidático "o saci e a reciclagem do lixo" de Samuel Muriel Branco;

Leitura do poema "paraíso" José Paulo Paes. Dividir a classe em quatro grupos para discutirem cada um dos dois itens: o que você faria:

Se a rua fosse sua

Se a mata fosse sua

Se o rio fosse seu.

Procurar em jornais notícias que mostrem problemas ambientais e desenvolver uma atividade de reflexão com a classe.

Elaborar cartazes para serem expostos nas dependências das escolas;

Produção de textos sobre o tema reciclagem.

\subsubsection{Ciências}


Os alunos desenvolverão atividades variadas sobre o livro paradidático "O saci e a reciclagem do lixo" de Samuel Muriel Branco.

Atividades em grupo sobre doenças que pode ser causa através do acúmulo de lixo: para desenvolver este item os alunos terão que fazer uma pesquisa sobre o assunto;

Confecção de trabalhos com materiais recicláveis;

Passeio ecológico com observação da realidade ambiental.

\subsubsection{Artes}

Oficina de reutilização em que os alunos poderão criar com garrafas pet, caixas, etc. Desenhos variados o tema reciclagem.

\subsubsection{História}

Trabalhar o capítulo VI da constituição brasileira sobre meio ambiente fazendo comparações com reportagem de jornais ou revistas sobre a situação atual do meio ambiente.

\subsubsection{Matemática}

Estudo das formas geométricas com matérias reciclados;

Gráfico feito com os alunos sobre o tempo que a natureza leva para absorver os detritos.

\subsubsection{Geografia}

Problema do lixo no mundo;

Passos básicos para reciclar;

Percursos dos recicláveis;

O que reciclar. 


\subsubsection{Inglês}

Canção "Reduce, Reuse e Recycle."

As atividades mencionadas acima têm por finalidade desenvolver nos alunos uma sensibilidade sobre as questões ambientais e principalmente sobre o lixo e as formas de reciclagem, reutilização e redução.

Notamos que para o desenvolvimento do projeto nem sempre necessitamos de materiais diferenciados que se encontram fora da realidade escolar, para as atividades citadas acima como exemplo, à maioria deles são materiais bem simples que já se encontram inseridos em nossas escolas como: Poemas; Letras de Música; Jornais; Livros Paradidáticos; Garrafas Pet; Caixas de Papelão; Fotos; Tesoura; Papel 40; Fita Adesiva; Cartolina; Lápis Coloridos; Tinta guache; Pincéis; Rádio; Folhas A4; Constituição Brasileira.

\subsection{A avaliação de um projeto}

Dentre da proposta apresentada, o que se propõe a uma conscientização sobre o cuidado com o meio ambiente, na qual as disciplinas são integradas como parte de um todo e incluirão os princípios formadores da consciência individual, social e planetária, apoia-se a ideia de trabalhar de forma diferenciada temas que não são destacados o suficiente. Essa forma de abordagem supre a necessidade de introduzir temáticas que são consideradas de pouca importância para o currículo escolar, mas que são de extrema urgência para a formação de uma sociedade justa e atuante na resolução de seus problemas.

A partir do momento que formamos indivíduos com capacidade para transformar a realidade atual, conscientes da sua responsabilidade em transformar o mundo num lugar melhor para se viver, teremos a chance de reverter, ou pelo menos minimizar os danos causados ao planeta.

A participação dos alunos é marcante em todo o desenrolar do projeto, pois a partir do momento que eles param para pensar na situação em que estão e o que poderá 
acontecer se passarem a ver o problema de outra perspectiva, entendendo que se cada um fizer sua parte e incentivar o outro a fazer a dele também, a mudança realmente ocorrerá. Ao constatarem na prática o que o desmatamento e os maus hábitos como; deixar a torneira aberta, passar muito tempo no banho, jogar lixo nas ruas etc., podem causar diversos danos a toda a sociedade eles desenvolverão uma consciência crítica a respeito do papel que realmente têm em relação à mudança que o planeta necessita.

A avaliação deverá ser contínua, através de observação e registro da participação e envolvimento de cada aluno, e assim de uma forma geral, poderemos perceber que os alunos serão conscientes de suas atitudes e se preocuparão com questões ambientais. Estando até dispostos a participar de campanhas que sejam relacionados com essas questões ambientais.

É claro que existem muitas questões que não serão valorizadas como deveriam ser, como a utilização da água e o consumo de energia exagerados, a separação de lixos, entre outras. A aprendizagem será percebida principalmente quando eles passarem a apagar as luzes da sala quando a aula acabar ou quando não será mais necessário, quando as torneiras dos banheiros estiverem bem fechadas e o lixo das salas diminuírem, entre tantas outras atitudes que podem ser acompanhadas no cotidiano escolar. Mais acima de tudo a avaliação será feita acima da evolução individual de cada aluno dentro de suas dificuldade e limitações.

\section{CONCLUSÕES}

Ao trabalhar o meio ambiente por um projeto, o professor torna-se mediador de ideias provocando em seus alunos novos sentidos e curiosidade, expandindo o conhecimento a muito além do que se tinha planejado. Obtendo resultados concretos que por meio do projeto serão inseridos ao cotidiano de seus alunos, alterando hábitos, ensinando valores, mudando a relação do aluno com si próprio, com o outro e com o mundo a sua volta. Portanto, desenvolver um projeto como esse não trabalha apenas conteúdos gerando saberes e sim forma opiniões, geram reflexões e transformam a relação 
homem-meio ambiente, formando cidadão críticos, responsáveis e que busquem sempre o desenvolvimento sustentável. (CORTEZ, 2013).

Concluímos com as reflexões trazidas por Dias, et al (2000) que trabalhar o tema meio ambiente para os alunos do ensino fundamental por meio de um projeto, é uma forma da escola pensar em um futuro melhor para todo o mundo, pensando nos frutos que esse projeto dará, é uma forma da escola contribuir para um mundo melhor, colocando em prática uma transformação na consciência e na qualidade de vida humana. É colaborar com ideias, conceitos, métodos, técnicas e experiências, saindo do meramente curricular e proporcionando o aprendizado por vivência, trazendo o problema para a realidade de seus alunos, levando-os a reflexão de possíveis soluções e de nosso papel como cidadão.

Esse trabalho, buscar muito mais que formar profissionais qualificados, e sim formar uma sociedade melhor para todos por meio da formação de pessoas aptas a viverem em sociedade e capazes de estimularem e disseminarem a cidadania e a consciência ambiental garantindo assim o desenvolvimento sustentável a nossa sociedade e a existência das gerações futuras.

A Educação Ambiental é um componente essencial e permanente da educação Nacional, devendo estar presente em todos os níveis e modalidades do processo educativo formal e não formal contribuindo para avaliação crítica, a adequação dos conteúdos à realidade local e o envolvimento dos educando em ações concretas de transformação desta realidade.

Segundo Albanus (2012, pg.111), "para trabalharmos o meio ambiente de forma transversal é necessário criar uma visão global e abrangente que inclua todas as disciplinas que espalhe por meio de uma pratica educativa global e abrangente de educação sustentável, viabilizando a formação de conceito e valores".

A questão ambiental tornou-se um tema preocupante e urgente a ser trabalhada, devidos aos inúmeros casos de desastres que vem ocorrendo no mundo todo. Em todos os lugares, podemos ver material recicláveis espalhados pela natureza, como garrafas, 
latas, papel, vidros, etc. Acredita-se que a educação tem o poder de promover uma grande mudança para o futuro do planeta, tendo em vista que a "educação forma tanto o povo, quanto os seus líderes. (ALBANUS,2012, pág. 17).

De acordo Albanus (2012) o histórico da relação do homem com o ambiente tem evoluído de forma descontrolada nos últimos tempos, devido ao advento da industrialização e do capitalismo, resultando na utilização desregrada de matérias-primas e na destinação incorreta dos resíduos gerados pelo processo de produção, elevando assim os índices de degradação do ambiente.

O projeto interdisciplinar utilizando-se dos recursos tecnológicos surgiu com o objetivo de despertar a consciência ecológica em cada ser humano, favorecendo um conhecimento que pudesse permitir uma mudança de comportamento voltado à proteção da natureza como um todo. A necessidade de trabalhar esses conceitos é divido ao grande número de catástrofes ambientais como o caso de Mariana em 2015, uns dos maiores desastres ambientais ocorrido em nosso país.

A Agenda 21, resultado da Conferência das Nações Unidas sobre o Meio Ambiente e Desenvolvimento, também preocupada como meio ambiente, cita que,

"O manejo ambientalmente saudável desses resíduos deve ir além do simples depósito ou aproveitamento por métodos seguros dos resíduos gerados e buscar resolver a causa fundamental do problema, procurando mudar os padrões não sustentáveis de produção e consumo" (p. 188).

Vivemos em um mundo, onde as pessoas consomem mais e mais, sem perceber o que isso está gerando no ambiente. Consumindo e descartando o lixo de maneira inadequada, sendo ele, o próprio homem o maior prejudicado de todos. Umas das maneiras que o ser humano pode contribuir para amenizar esses problemas e a reciclagem do lixo, aproveitando alguns materiais para fabrica-los outros.

Segundo VALLE (1995: 71), "reciclar o lixo significa refazer o ciclo, permite trazer de volta, à origem, sob a forma de matéria-prima aqueles materiais que não se degradam 
facilmente e que podem ser reprocessados, mantendo as suas características básicas". Sendo assim não gerará acúmulos de lixo que possa causar danos ao ambiente.

\section{AGRADECIMENTOS}

Agradecimentos a revisores, colaboradores e agências de fomento.

\section{REFERÊNCIAS}

ALBANUS, L.L.F.; ZOUVI, C.L. Eco pedagogia: educação de meio ambiente. Curitiba. InterSabere, $2012 . \quad$ Disponível em: http://bv4.digitalpages.com.br/?term=ecopedagogia\&searchpage $=1 \&$ filtro =todos \&from $=$ bus ca\#/edicao/3246.

AUSUBEL, David Paul. A aprendizagem significativa: a teoria de David Ausubel. São Paulo: Moraes, 1982.

CHAVES, E., O., C.O que é um projeto interdisciplinar? Educação Pública. Disponível em: http://www.educacaopublica.rj.gov.br/biblioteca/educacao/0026.html.

CONCEITOS DE EDUCAÇÃO AMBIENTAL. Ministério do meio ambiente. Disponível em: http://www.mma.gov.br/educacao-ambiental/politica-de-educacao-ambiental.

CONHEÇA OS MAIORES DESASTRES AMBIENTAIS DO BRASIL. Nos últimos 30 anos, uma série de desastres ambientais acarretaram em grandes danos para a população. Disponível em: https://www.terra.com.br/noticias/mundo/conheca-os-5-piores-desastres-ecologicos-daatualidade,e35c27721cfea310VgnCLD200000bbcceb0aRCRD.html\&gt;. Acesso em: 28 jun. 2018.

CORRÊA, H, LIMA, S, e GOMIDE , R. Mariana: os dramas e as culpas pela tragédia. Um dos maiores desastres ambientais do país faz um povoado desaparecer, arrasa um rio e mostra que 0 Brasil precisa punir com mais rigor (20/11/2015). Disponívelem: https://epoca.globo.com/tempo/noticia/2015/11/mariana-os-dramas-e-culpaspela-tragedia.html. Acesso em 28, jun 2018.

CORTEZ, C. O que um bom projeto para a educação infantil precisa ter? Nova Escola. 2013. Disponível em: https://novaescola.org.br/conteudo/50/o-que-um-bom-projeto-paraeducacao-infantil-deve-ter. 
DIAS, G. F. et al. Educação ambiental. Princípios e práticas, 6a Edição. São Paulo: Editora Gaia, 2000.

Disponível

em:https://www.researchgate.net/profile/Antonio_Fluminhan/publication/309179299_Utilizaca o_do_Acervo_Educacional_de_Ciencias_Naturais_da_Unoeste_para_a_Educacao_Ambiental/link s/5803024408ae310e0d9dec44/Utilizacao-do-Acervo-Educacional-de-Ciencias-Naturais-daUnoeste-para-a-Educacao-Ambiental.pdf.

FERNANDES, Elisangela. David Ausubel e a aprendizagem significativa. 2011. Disponível em: https://novaescola.org.br/conteudo/262/david-ausubel-e-a-aprendizagem-significativa. Acesso em: 25 out. 2018.

FRANCIOSI, B. R. T. I., MEDEIROS, M. F., COLLA, A. L. Caos, criatividade e ambientes de aprendizagem. Educação a Distância-Cartografias Pulsantes em Movimento. Porto Alegre: EDIPUCRS, 2003, p. 129-149.

FREIRE, Paulo. Pedagogia do oprimido. 36 ed. Rio de Janeiro: Paz e Terra, 2003.

FREIRE, Paulo. Pedagogia da autonomia: saberes necessários à prática educativa. São Paulo: Paz e Terra, 1996.

LOCATELLI, T. A Utilização de Tecnologias no Ensino da Química. Revista Científica Multidisciplinar Núcleo do Conhecimento. Ano 03, Ed. 08, Vol. 04, pp. 5-33, 2018. Disponível em: https://www.nucleodoconhecimento.com.br/educacao/tecnologias-no-ensino.

MASETTO, Marcos Tarciso. (Org.) Docência na Universidade. Campinas: Papirus, 2013.

MELARÉ, Daniela. Estilos de uso do espaço virtual: como se aprende e se ensina no virtual? Inter-Ação, Goiânia, v.1, n.34, p. 51-74, jan.-jun. 2009. Disponível em: https://www.revistas.ufg.br/interacao/issue/view/688/showToc. Acesso em: 25 out. 2018.

MOURA, D., G.; BARBOSA, E., F. Trabalhando com projetos: planejamento e gestão de projetos educacionais. Editora Vozes Limitada, 2017. Disponível em: https://books.google.com.br/books?hl=pt-

$B R \& \mid r=\& i d=W 9 Q 5 D w A A Q B A J \& o i=$ fnd \&pg $=$ PT5\&dq $=$ projetos + educacionais\&ots $=C B b B O g S$ RML\&sig=6_a8tjcDTQTSuDXr7kkTaS6OwN4\#v=onepage \&q=projetos\%20educacionais\&f $=$ fal se.

MOÇO, A. 14 perguntas e respostas sobre projetos didáticos. Nova escola. 2011. Disponível em: $\quad$ https://novaescola.org.br/conteudo/424/14-perguntas-e-respostas-sobre-projetosdidaticos.

MÚSICAS- LETRAS, chovendo na roseira (tom Jobim), planeta agua (Guilherme Arantes) planeta azul (Chitãozinho e Xororó) poemas - paraíso (José Paulo Paes), sou da natureza e separe (Berenice Gehlen Adams). Disponível em: http://www.vagalume.com.br/. 
PALLOFF, Rena M. e PRATT, Keith. Construindo Comunidades de Aprendizagem no Ciberespaço: Estratégias eficientes para salas de aula on-line. Porto Alegre: Artmed, 2002. $248 \mathrm{p}$.

PELLIZZARI, Adriana et al. Teoria da aprendizagem significativa segundo Ausubel. Rev. PEC, Curitiba, v.2, n.1, p.37-42, jul. 2001-jul. 2002. Disponível em: http://portaldoprofessor.mec.gov.br/storage/materiais/0000012381.pdf. Acesso em: 25 out. 2018.

PONTES, Elivelton. $\mathbf{O}$ que é o Moodle? Conheça esse ambiente virtual de aprendizagem, 20 de out. 2017. Disponível em:https://eadbox.com/o-que-e-moodle-como-funciona/. Acesso em: 15 nov. 2018

RELEMBRE OS PRINCIPAIS DESASTRES AMBIENTAIS OCORRIDOS NO BRASIL. Disponível em:http://www.ebc.com.br/noticias/meio-ambiente/2015/11/conheca-os-principais-

desastres-ambientais-ocorridos-no-brasil. Acesso em 28 jun. 2018.

SANTOS. Edméa Oliveira. Ambientes virtuais de aprendizagem: por autorias livres, plurais e gratuitas. In: Revista FAEBA, v.12, no. 18.2003

SILVA, Marco. Educar na cibercultura: desafios à formação de professores para docência em cursos online. Revista Digital de Tecnologias Cognitivas, PUC-SP. No 3, jan - jun. p. 36-51, 2010. Disponível em: http://www4.pucsp.br/pos/tidd/teccogs/artigos/2010/edicao_3/3educar_na_cibercultura-desafios_formacao_de_professores_para_docencia_em_cursos_onlinemarco_silva.pdf. Acesso em: 23 out.2018.

SOARES, A. L. A. Metodologia de ensino: projetos interdisciplinares. Brasil Escola. 2012. Disponível em: https://meuartigo.brasilescola.uol.com.br/educacao/metodologias-ensinoprojetos-interdisciplinares.htm. 